\title{
A new year, a new Journal
}

Let us start this first editorial of 2018 with wishing you all a marvelous year where most of your dreams come true. In the last years, the editors of Rhinology felt often very unhappy when again we had to refuse papers send to us for Rhinology. Unfortunately, every year we can only accept around $15 \%$ of the papers we receive. With pain in our hearts, we often have to refuse papers of good quality but just not innovative enough or with slight methodological imperfections.

The editorial board of Rhinology recognized this feeling and we decided to start a new journal: Rhinology Online to have space for all those papers that are good but just do not make the cut for Rhinology. Rhinology Online is a journal of the European Rhinologic Society, and will provide a platform for the dissemination of rhinologic research and reviews, as well as position papers, task force reports and guidelines, amongst an international scientific audience.

Rhinology Online is a peer-reviewed, Open Access journal that will accept original research articles, review articles, protocols of clinical studies, letters to the editor, position papers, task force reports and guidelines and case reports in rhinology. Open access publishing enables free access to all content ensuring a wide dissemination of articles; the electronic format and expert peer review allows for very rapid publication. Publications will be available in Pubmed within a week after acceptance. Rhinology Online is an international journal reaching out far beyond the borders of Europe, and invites clinicians and researchers from all countries of the world to contribute.

We look forward to have a modern lively journal with a lot of discussion. Please have look at the website: www.rhinologyonline.org and start sending in your papers.

In this issue of Rhinology, a number of very interesting papers can be found. Two systematic reviews are presented. One on the effect of intranasal bevacizumab in the treatment of Hereditary haemorrhagic telangiectasia $(\mathrm{HHT})$ - related epistaxis. Bevacizumab is a selective recombinant human antibody against VEGF - A isomers. It has also become first-line treatment for symptomatic hepatic AVMs in HHT, and based on this success, several studies have analysed the effect of bevacizumab on other HHT outcomes including epistaxis ${ }^{(1)}$. However, despite initial promising results, it remains unclear whether the agent provides any true benefit in epistaxis outcome ${ }^{(1)}$. Two years ago, the same authors published an excellent overview of all potential treatment options in $\mathrm{HHT}^{(2)}$ in which they presented a treatment algorithm based on tamoxifen, followed by/ combined with ktp laser, septodermoplasty and finally nasal closure by the Lund modification of the Young's procedure ${ }^{(3)}$. The other review is very timely and summarizes the possibilities to treat CRSwNP with monoclonal antibodies. In the last years a number of studies has appeared that show effectiveness of anti-IgE (Omalizumab) (4-6), anti-IL-5 (Mepolizumab) ${ }^{(7)}$ and antiIL4R $\alpha$ (Dupilumab) ${ }^{(8)}$.

In CRSwNP our medical treatment options are limited and when local treatment with corticosteroids are not effective at the moment we have to choose between systemic corticosteroids and surgery or both. We know that pre-operative use of local and/or systemic corticosteroids, results in reduced blood loss, shorter operative time and improved surgical field quality. Moreover, postoperative corticosteroids improve postoperative endoscopic scores in CRS and recurrence rates in cases of CRSwNP ${ }^{(9,10)}$. We also know that CRS has a significant impact on QOL and interestingly that different types of CRS symptoms - most prominently otologic/facial pain and sleep-related symptoms - and their underlying pathophysiologic mechanisms may differentially affect the general health-related QOL detriment associated with CRS ${ }^{(11-14)}$. We also know that FESS has significant positive effects on most aspects of quality of life (14-16) including sleep ${ }^{(17,18)}$.

On the downside, we are more and more aware of the potential serious side effects of systemic corticosteroids also when used in short courses ${ }^{(19,20)}$. Moreover, we do not know when exactly the choice for surgery has to be made over systemic Corticosteroids. To find an answer to that question at least two randomized studies are performed at the moment one in The Netherlands (21) and one in the UK. In general, of course we want to avoid surgery when possible and the new possibilities of monoclonal antibodies will gain a significant place in our armamentarium in the near future.

Therapies with monoclonal antibodies are targeting one specific pathophysiological pathway or endotype. This endotypedriven treatment approach requires careful selection of the patient population who might benefit from a specific treatment ${ }^{(22,23)}$. Personalized medicine is addressing the issue of providing targeted treatment for the right patient and should be seen as one aspect of the promising trend towards precision medicine ${ }^{(24,25)}$. For now, in the airways, these expensive treatments are only available for patients with severe asthma but we may hope and expect that in the near future also patients with severe CRS can benefit.

When evaluating treatment, it is extremely important to have a Core outcome set (COS) to report. A COS is an agreed, standardized set of outcomes that should be measured and reported 
by trials as a minimum and will facilitate future meta-analysis of trial results in systematic reviews. We earlier suggested a COS in EPOS2012 ${ }^{(26)}$, and in last year in this Journal the most important outcomes for systematic reviews of interventions for rhinosinusitis in adults were presented ${ }^{(27)}$. In this issue of the Journal a group of authors led by Claire Hopkins using an e-Delphi iterative process allowing 110 patients and healthcare practitioners to individually rate the outcomes in terms of importance, now advise a core-outcome set for trials of 15 items, over 4 domains: the CHROME outcome set ${ }^{(28)}$. The authors hope inclusion of these core outcomes in future trials will increase the value of research on interventions for CRS in adults. Rhinology and Rhinology online will emphasize the use of CHROME.

For now, we wish you a lot of reading, learning and fun with our two new Journals.
1. Stokes P, Rimmer J. Intranasal bevacizumab in the treatment of HHT - related epistaxis: a systematic review. Rhinology. 2018; 56(1): 3-10.

2. Rimmer J, Lund VJ. Hereditary haemorrhagic telangiectasia. Rhinology. 2015;53(2):12934.

3. Lund VJ, Darby Y, Rimmer J, Amin M, Husain S. Nasal closure for severe hereditary haemorrhagic telangiectasia in 100 patients. The Lund modification of the Young's procedure: a 22-year experience. Rhinology. 2017:55(2):135-41.

4. Vennera Mdel C, Picado C, Mullol J, Alobid I, Bernal-Sprekelsen M. Efficacy of omalizum$\mathrm{ab}$ in the treatment of nasal polyps. Thorax. 2011;66(9):824-5.

5. Gevaert P, Calus L, Van Zele T, et al. Omalizumab is effective in allergic and nonallergic patients with nasal polyps and asthma. J AllergyC lin Immunol. 2013;131(1):110-6.e1

6. Bidder T, Sahota J, Rennie C, Lund VJ, Robinson DS, Kariyawasam $\mathrm{HH}$. Omalizumab treats chronic rhinosinusitis with nasal polyps and asthma together-a real life study. Rhinology. 2018; 56(1): 42-45.

7. Bachert C, Sousa AR, Lund VJ, et al. Reduced need for surgery in severe nasal polyposis with mepolizumab: Randomized trial. AllergyC lin Immunol. 2017;140(4):1024-31. e14.

8. Bachert C, Mannent L, Naclerio RM, et al. Effect of Subcutaneous Dupilumab on Nasal Polyp Burden in Patients With Chronic Sinusitis and Nasal Polyposis: A Randomized Clinical Trial. JAMA. 2016;315(5):469-79.

9. Pundir V, Pundir J, Lancaster $G$, et al. Role of corticosteroids in Functional Endoscopic Sinus Surgery--a systematic review and meta-analysis. Rhinology. 2016;54(1):3-19.

10. Head K, Chong LY, Hopkins C, Philpott C, Burton MJ, Schilder AG. Short-course oral steroids alone for chronic rhinosinusitis. The Cochrane database of systematic reviews. 2016:4:Cd011991.

11. Hoehle LP, Phillips KM, Bergmark RW, Caradonna DS, Gray ST, Sedaghat AR. Symptoms of chronic rhinosinusitis differentially impact general health-related quality of life. Rhinology. 2016;54(4):316-22.
12. Jiang RS, Liang $\mathrm{KL}$, Hsin $\mathrm{CH}$, Su MC. The impact of chronic rhinosinusitis on sleep-disordered breathing. Rhinology. 2016;54(1):75-9

13. Phillips KM, Hoehle LP, Bergmark RW, et al Chronic rhinosinusitis severity is associated with need for asthma-related systemic corticosteroids. Rhinology. 2017;55(3):211-7.

14. Sahlstrand-Johnson P, Hopkins C, Ohlsson $B$, Ahlner-Elmqvist M. The effect of endoscopic sinus surgery on quality of life and absenteeism in patients with chronic rhinosinuitis - a multi-centre study. Rhinology. 2017;55(3):251-61

15. Alt JA, Smith TL, Schlosser RJ, Mace JC, Soler ZM. Sleep and quality of life improvements after endoscopic sinus surgery in patients with chronic rhinosinusitis. Int Forum Allergy Rhinol. 2014;4(9):693-701.

16. Zhang Z, Adappa ND, Doghramji LJ, et al. Quality of life improvement from sinus surgery in chronic rhinosinusitis patients with asthma and nasal polyps. Int Forum Allergy Rhinol. 2014;4(11):885-92.

17. Nguyen DT, Arous F, Gallet P, et al. Sinonasal symptom-related sleep disorders before and after surgery for nasal polyposis. Rhinology. 2017;55(3):262-8.

18. Varendh M, Johannisson A, Hrubos-Strom $H$, Andersson M. Sleep quality improves with endoscopic sinus surgery in patients with chronic rhinosinusitis and nasal polyposis. Rhinology. 2017;55(1):45-52.

19. Waljee AK, Rogers MA, Lin P, et al. Short term use of oral corticosteroids and related harms among adults in the United States: population based cohort study. BMJ (Clinical research ed). 2017;357:j1415.

20. Winblad L, Larsen CG, Hakansson K Abrahamsen B, von Buchwald C. The risk of osteoporosis in oral steroid treatment for nasal polyposis: a systematic review. Rhinology. 2017;55(3):195-201.

21. Lourijsen ES, de Borgie CA, Vleming $M$, Fokkens WJ. Endoscopic sinus surgery in adult patients with chronic rhinosinusitis with nasal polyps (PolypESS): study protocol for a randomised controlled trial. Trials. 2017;18(1):39

22. Lou H, Meng Y, Piao Y, et al. Cellular phenotyping of chronic rhinosinusitis with nasal polyps. Rhinology. 2016:54(2):150-9

23. De Greve G, Hellings PW, Fokkens WJ, Pugin B, Steelant B, Seys SF. Endotype-driven treatment in chronic upper airway diseases. Clin Transl Allergy. 2017;7:22.

24. Hellings PW, Fokkens WJ, Bachert C, et al. Positioning the principles of precision medicine in care pathways for allergic rhinitis and chronic rhinosinusitis - A EUFOREAARIA-EPOS-AIRWAYS ICP statement. Allergy. 2017;72(9):1297-305.

25. Hellings PW, Akdis CA, Bachert C, et al. EUFOREA Rhinology Research Forum 2016: report of the brainstorming sessions on needs and priorities in rhinitis and rhinosinusitis. Rhinology. 2017:55(3):202-210.

26. Fokkens WJ, Lund VJ, Mullol J, et al. European Position Paper on Rhinosinusitis and Nasal Polyps 2012. Rhinology Supplement. 2012(23):3 p preceding table of contents, 1-298.

27. Hopkins C, Philpott C, Crowe S, et al. Identifying the most important outcomes for systematic reviews of interventions for rhinosinusitis in adults: working with Patients, Public and Practitioners. Rhinology. 2016;54(1):20-6

28. Hopkins C, Hettige R, Soni-Jaiswal A, et al. CHronic Rhinosinusitis Outcome MEasures (CHROME) - developing a core outcome set for trials of interventions in chronic rhinosinusitis. Rhinology. 2018; 56(1): 22-33.

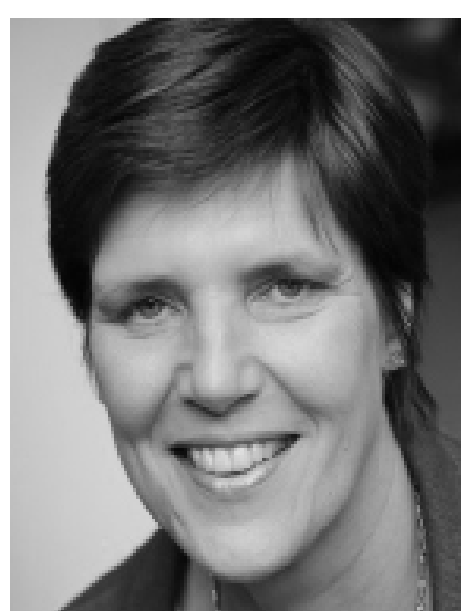

